\title{
A resignificação da crise ambiental pela mídia de negócios: responsabilidade empresarial e redenção pelo consumo
}

\author{
Isleide A. Fontenelle
}

Resumo: $\mathrm{O}$ artigo analisa como o consumidor ambientalmente responsável tem sido produzido pela mídia de negócios em duas revistas: The Economist e Exame, no período de 1996-2007. O método de pesquisa apoia-se na Teoria do Discurso de Ernesto Laclau e Chantal Mouffe e em autores lacanianos que encamparam essa teoria. A análise empírica, apoiada por uma revisão bibliográfica sobre crise ambiental, consumo e responsabilidade empresarial, permite concluir que a construção midiática do consumidor responsável tem se utilizado da culpabilização presente no discurso da crise ambiental para vender redenção como mercadoria.

Palavras-chave: consumo responsável; responsabilidade social corporativa; crise ambiental; culpa; redenção

Abstract: Resignification of the environmental crisis by the business media: corporate responsibility and redemption through consumption - This article examines how the environmentally responsible consumer has been 'produced' by the business media, based on an analysis of two magazines in the period of 1996-2007: Britain's The Economist and Brazil's Exame. The research method is based on the Discourse Theory founded by Ernesto Laclau and Chantal Mouffe and on Lacanian authors who adopted this theory. An empirical analysis, underpinned by a bibliographic review of the relationships between environmental crisis, consumption and social corporate responsibility, allows us to conclude that the media's construction of the responsible consumer exploits the notion of culpability in the discourse of the environmental crisis to peddle redemption as a commodity.

Keywords: responsible consumption; social corporate responsibility; environmental crisis; guilt; redemption 


\section{Introdução}

A temática do consumo tem se destacado na produção discursiva sobre a crise ambiental e o ato de consumir passou a ser imbricado com questões de mitigação de danos causados ao meio ambiente. Porém, a forma pela qual esse discurso da responsabilidade do consumidor vem sendo produzido ganha diferentes contornos. Nos discursos empresariais é o consumidor individual que é ressaltado na busca pela construção de uma sustentabilidade corporativa. O enfoque quase sempre remete a uma discussão sobre o papel do indivíduo em suas decisões de consumo (HOLT, 2002; CARUANA e CRANE, 2008; CONNOLLY e PROTHERO, 2008). O discurso de defesa do meio ambiente é articulado às estratégias de responsabilidade social corporativa, visando atingir um consumidor disposto a realizar uma escolha que atribua valor às estratégias empresariais. O consumidor é saudado como empoderado, capaz de escolher e assumir essas escolhas (SHAW et al., 2006).

Pesquisas, entretanto, já questionam o alcance desse consumidor: o estudo desenvolvido por Caruana e Crane (2008), que buscou entender o papel das corporações em construir a natureza, o significado e as implicações da "responsabilidade do consumidor", evidencia a importância que as corporações tem tido na formatação desse consumidor necessário às novas relações entre consumo e meio ambiente. Os autores questionam tal papel, sugerindo que ele emerge de um marketing técnico, altamente institucionalizado, cujo discurso é predisposto a diferenciar, posicionar e permitir a escolha do consumidor. Na pesquisa que Connolly e Prothero (2009) desenvolveram junto a "consumidores verdes", os autores concluíram que o sentimento de empoderamento é acompanhado por incertezas sobre a coisa certa a fazer, misturando-se a sentimentos de ambivalência e culpa.

Este artigo se insere na tradição desses estudos que refletem sobre os limites da responsabilização do consumidor, em especial na maneira como ele vem sendo resignificado pelo discurso midiático. Tendo em vista a questão climática que colocou a relação entre consumo e meio ambiente na agenda pública, partimos do pressuposto de que a mídia de negócios tem sido um ator de peso na construção do discurso do consumidor responsável pelo meio ambiente que atenda aos interesses do mundo mercadológico (YEARLEY, 1991; JORGENSEN e PHILLIPS, 2009; CORBUCCI, 2011). Entendemos a mídia de negócios como espelho do mundo corporativo, refletindo e resignificando certas práticas organizacionais e mercadológicas que já estão em operação.

Apresentaremos uma pesquisa realizada junto à mídia de negócios a fim de compreender como o consumidor ambientalmente responsável tem sido produzido nesse contexto. Foram analisadas duas revistas: a britânica The Economist e a revista brasileira Exame no período de 1996 a 2007.

Exame é uma revista importante na divulgação de práticas do mundo corporativo, afirmando em seu perfil editorial que é a "líder brasileira de publicidade e de circulação 
entre as revistas de negócios e que leva aos seus qualificados leitores análises profundas sobre os principais acontecimentos do mundo dos negócios". (http://publicidade.abril. com.br/marcas/exame/revista/informacoes-gerais)

The Economist é uma publicação que tem articulado o debate internacional em torno dessa questão. Em seu perfil editorial a revista afirma que é um semanário de notícias internacionais e de publicação de negócios e que é lida por mais líderes mundiais políticos e empresariais do que qualquer outra revista. (http://www.economistgroup.com/ what_we_do/our_brands/the_economist_brand_family/the_economist.html).

Nosso objetivo é analisar o discurso que essas duas revistas vêm produzindo sobre o que é o consumidor ambientalmente responsável. Iniciaremos com alguns fundamentos epistemológicos, teóricos e metodológicos que subsidiaram a pesquisa e apresentaremos alguns dados sobre como o discurso da responsabilidade ambiental do consumidor emergiu nas revistas a partir da relação entre culpa e redenção pelo mercado. Em seguida, discutiremos como o discurso midiático vem se apropriando do discurso mais amplo da crise ambiental e resignificando a ideia de responsabilidade do consumidor.

\section{Fundamentos epistemológicos, teóricos e metodológicos}

Este artigo é guiado pela premissa epistemológica de que discursos são construções contingentes de realidade, alinhada a uma perspectiva psicanalítica lacaniana, em especial à concepção de Real e da inconsistência do Outro (LACAN, 2008). O Outro é o campo simbólico, espaço no qual os discursos buscam se constituir e se firmar como verdades incontestáveis. O Real é o excesso que não pode ser simbolizado e que, portanto, perturba o campo simbólico, na medida em que revela que há sempre incompletude e inconsistência no Outro. Ao Real, diz Lacan, não falta nada (LACAN, 2005).

Segundo o filósofo Slavoj Žižek - um dos mais destacados intérpretes contemporâneos da leitura lacaniana do Real -, Lacan considerava a psicanálise "um método de leitura de textos, orais (a fala do paciente) ou escritos" (Žižek, 2010, p.12). No entanto, Lacan não desenvolveu propriamente um método que pudesse nos servir de guia nas análises dos discursos sociais contemporâneos. Esse empreendimento foi levado a cabo por Laclau e Mouffe (2001), fundadores de uma nova Teoria do Discurso e por seus continuadores, em especial aqueles que deram uma ênfase especial à teoria lacaniana (GLYNOS e STRAVAKAKIS, 2010; STRAVAKAKIS, 1997a; 1997b; 2000).

A teoria do discurso foi tomada como matriz direcionadora desta pesquisa, por não ser apenas um método de análise de dados. Uma de suas principais premissas está no fato de ser uma abordagem "dirigida por um problema", mais do que por método, sendo esta última abordagem "mais motivada por técnicas de coleta de dados e análise do que por uma problematização dada por um fenômeno empírico sob investigação" (GLYNOS e HOWARTH, 2007, p.167). 
Nossa pesquisa incorporou as influências lacanianas na construção do método de análise do discurso, em especial com a noção de "ponto nodal", que consiste em um "significante privilegiado que fixa o significado da cadeia significante" (LACLAU e MOUFFE, 2001, p. 112). Os "pontos nodais" visam dar conta do objetivo de qualquer discurso, que é o de se tornar dominante em certo campo social. Inspirados na teoria lacaniana da contingência imposta pelo Real, os autores da teoria do discurso compreendem que nenhum discurso é capaz de dominar completamente o campo da discursividade. A fixação de um discurso pelo ponto nodal é apenas parcial, embora "formações discursivas podem consistir de elementos relacionados que em certos contextos podem vir a ser compreendidos como uma totalidade" (HOWARTH, 2000, p.102).

Trabalhamos também com o conceito de deslocamento, que "põe no epicentro do discurso o que é desconsiderado em abordagens mais tradicionais: o elemento de negatividade inerente à experiência humana, o elemento de ruptura e crise que ameaça e subverte o campo da objetividade social" (STRAVAKAKIS, 2000, p.100). A concepção de deslocamento foi discutida em um texto posterior de Laclau (1999), na assunção de que os discursos são contingentes e estão continuamente submetidos aos efeitos de deslocamento de eventos sociais e políticos.

A leitura que Stravakakis faz sobre o "fator de deslocamento" é duplamente importante para os objetivos desta pesquisa, pois, além de se apoiar na teoria do discurso, o autor também se debruça sobre a emergência da "ideologia verde" como um novo paradigma ambiental. Ao invés de buscar a emergência dessa nova ideologia em "causas positivamente existentes e explanações racionais", o autor lança mão da noção de deslocamento como "o momento de falha e subversão do sistema de representação que introduz uma ruptura na ordem normal - ou normalizada - das coisas" (STRAVAKAKIS, 2000, p.105-106). Para Stravakakis (2000), a emergência da "ideologia verde" se deu em função de um

vazio criado pelo deslocamento de nossas concepções imaginarias e simbólicas da natureza, gerando um sentimento de crise ambiental; um vazio que coincidiu com outro vazio criado pelo deslocamento de certas correntes do discurso ideológico, presentes no espectro político radical (idem, p.107).

De acordo com Laclau (1999, p.39), deslocamentos "são fundações sobre as quais novas identidades são constituídas". Ao criar um vazio no nível dos significados, um deslocamento promove "novas construções discursivas que tentam suturar a estrutura deslocada" (HOWARTH e STRAVAKAKIS, 2000, p.13). O deslocamento que resultou no novo paradigma ambiental vem sendo continuamente resignificado e tem ganhado contornos diferenciados nos discursos empresariais contemporâneos, em especial, sobre o consumo ambientalmente responsável. 


\section{A pesquisa empírica: o discurso da mídia de negócios}

Considerando a extensão do período de análise das duas revistas, optamos por um software de apoio de leitura de textos (Atlas T.I). Para o primeiro levantamento, listamos um conjunto de termos a fim de que eles fossem suficientemente abrangentes para dar conta das publicações nas duas revistas pesquisadas: consumo/consumidor consciente; verde; sustentável; ético-ativista; eficiente-racional; saudável; responsável. Esses termos seriam, na acepção da teoria do discurso, "elementos", "os signos cujos significados não foram ainda fixados; signos que tem múltiplos, potenciais significados" (JORGENSEN e PHILLIPS, 2002, p.27). Ao final, escolhemos o termo consumidor responsável por acreditarmos que ele engloba todos os sentidos anteriores. Os arquivos coletados foram padronizados, tratados para remoção de marcas e figuras e colocados em padrão aceitável no Atlas T.I. Em seguida, foram consolidados por ano e transformados em documentos primários de análise. A partir dos resultados desse primeiro relatório, verificamos que muitas reportagens não traziam relação nenhuma com a questão ambiental, sendo, portanto, excluídas.

Em um segundo momento, foram elencados outros termos que poderiam apontar para a existência de discursos em torno do consumidor responsável, mesmo que os termos-base não estivessem expressamente mencionados: Greenpeace, WWF (World Wild Forum), aquecimento global, mudanças climáticas, movimentos ambientais, protocolo de Kyoto, IPCC (Intergovernamental Pannel on Climate Change), meio ambiente, sustentabilidade, ecologia, reciclagem, empresas ambientalmente responsáveis, tecnologia limpa. Esses termos adicionais foram mapeados na medida em que vinham fortemente associados aos termos-base no primeiro relatório. Por exemplo: junto a "consumo verde", termos como ecologia, ecologismo, Greenpeace, $W W F$, apareciam constantemente, formando uma nova rede. Estes termos serviram de base para novas buscas e o processo continuou iterativamente até as buscas pararem de trazer novas citações de interesse para a pesquisa. À medida que esses novos termos foram incluídos no estudo, foram também articulados em mapas conceituais temáticos.

Para cada termo-base foi emitido um relatório para que, a partir dele, fosse feita uma análise detalhada sobre as reportagens nas quais eles estavam contidos, a fim de se tirar conclusões prévias (mudança do discurso ao longo do tempo, posicionamento sobre determinados agentes, comparação entre as duas revistas) e orientar a continuidade das análises.

A etapa seguinte consistiu na análise de discurso propriamente dita: fizemos uma leitura criteriosa de todas as reportagens finais, buscando compreender em que contexto as revistas mencionavam a temática do consumidor responsável. Os resultados obtidos nos levaram a trabalhar com alguns padrões de discursos, o que provocou a criação final de algumas categorias centrais de análises: movimentos ambientalistas; governo; ciência e tecnologia; mercado; empresas e consumidor individual. 
A partir dessa leitura final, quando algumas categorias de análise permitiram uma associação clara com os temas da culpa e da redenção, buscamos o referencial teórico que nos permitisse analisar de que maneira seria possível discutir a questão da responsabilização do consumidor à luz do tema maior do consumo e da crise ambiental.

A análise a seguir, portanto, é uma interpretação das reportagens a partir das categorias elencadas como centrais na produção do discurso do consumidor ambientalmente responsável nas duas revistas analisadas: como ambas retratam os movimentos ambientalistas?; como veem o papel do governo?; como se posicionam com relação às saídas pela ciência e tecnologia?; como veem as oportunidades de mercado? e, finalmente, como atribuem papéis às empresas e ao consumidor? É somente a partir desse contexto - e de sua interpretação - que o discurso da culpa e da redenção emergirá e poderá ser discutido à luz da teoria adotada.

\section{Crise ambiental: o papel reservado às empresas e consumidores}

Um "ponto nodal" - "a noção de um elemento particular assumindo o funcionamento de uma estrutura universal no contexto de um dado campo discursivo" (LACLAU e MOUFFE, 2001, p.xi) - encontrado na construção discursiva da mídia de negócios foi "ambiente", articulado à ideia de que a natureza está em crise e de que é preciso que algo seja feito. Empresas e consumidores aparecem como agentes morais fundamentais desse processo. $\mathrm{O}$ discurso ambiental é articulado a um discurso organizacional focado na responsabilidade social corporativa, bem como a um discurso que aponta para um tipo de consumidor moralmente engajado na resolução da crise ambiental. Consumir de empresas socialmente responsáveis seria o caminho viável para um consumidor também responsável.

Nessa construção discursiva outros discursos sobre a crise ambiental são excluídos, o que pode ser claramente compreendido a partir da lógica do "antagonismo social" da teoria do discurso: "formações sociais dependem da construção de relações antagônicas entre os agentes sociais considerados 'inseridos' ou 'excluídos' de uma dada formação social" (HOWARTH, 2000, p.106). Ficou evidente a desqualificação aos movimentos ambientalistas em ambas as revistas, indicando que os mesmos não dispõem de informações suficientes e corretas sobre a situação ambiental, além de muitas vezes apresentarem interesses escusos. O discurso claramente indica que o caminho para um consumo responsável não passa pelo conflito e pelo protesto político. No caso da The Economist o tratamento mais crítico aos movimentos ambientalistas veio no contexto dos chamados movimentos anti-globalização, após a "Batalha de Seatle", em 1999.

Quanto ao governo, há uma relação aparentemente ambígua, com reportagens nas quais qualquer tipo de regulamentação é considerado censura ou intervenção ao livre mercado; ao mesmo tempo, há reportagens nas quais o governo é chamado a agir, havendo cobranças para que ele seja mais presente nas respostas à crise ambiental, com a indicação 
de que o mesmo tem sido incapaz de fazê-lo, daí a necessidade das empresas agirem em seu lugar. Embora The Economist seja menos ufanista, algumas vezes questionando se as empresas estariam à altura desse papel, essa visão prevaleceu.

Enquanto atores como governo e sociedade civil são resignificados a partir de um discurso de desqualificação, as empresas vão se apresentando com um papel centralmente positivo. Há uma certeza na resolução da crise ambiental com o uso da tecnologia atrelado a iniciativas empresariais de sucesso. A crise ambiental apresenta-se, como uma grande oportunidade de negócios; e o empreendedorismo, em especial na revista brasileira, é altamente destacado.

Muitas empresas consideram ganhar dinheiro com empreendimentos que ajudem a reduzir o aquecimento global, como centrais elétricas limpas, parques eólicos e hipotecas com taxas menores para casas que neutralizem suas taxas de carbono... (CAN, 2006).

A preservação do planeta pode ser a maior oportunidade de negócios deste século (TEIXEIRA JR, 2006).

É nesse contexto que se dá a construção do consumidor responsável, em diálogo permanente com as empresas ambientalmente responsáveis que só poderão sustentar esse papel tendo como contraponto um consumidor que também esteja moralmente engajado, que se sinta responsável e que saiba valorizar essas ações empresariais.

Nos últimos anos, os consumidores do Ocidente têm desenvolvido um sentido invertido do que é ser chique em função de sua conturbada consciência ambiental (BEYOND, 1998).

Se os consumidores derem preferência a produtos que protegem a natureza, os fabricantes que não mudarem seus produtos convencionais vão perder mercado (RICHERS, 1996).

Vejamos, agora, que significados a mídia de negócios atribui a categorias como responsabilidade e culpa.

\section{The Economist: um discurso ambiental que atribui responsabilidade ao consumidor através da culpabilização}

Embora em muitas reportagens The Economist apresente a figura idealizada do consumidor responsável adequado ao contexto empresarial, em outras assume um tom acusatório indicando que, embora essa responsabilidade seja necessária, o consumidor ainda não estaria moralmente engajado. Esses dados nos levaram a começar a operar com a perspectiva da produção da culpa. 
Um estudo acadêmico recente concluiu que, embora as empresas venham criando atitudes favoráveis para desfrutar de uma alta fidelidade à marca, os clientes ainda consideram atributos não-verdes mais importantes na tomada de suas decisões de compra (COMO, 2000).

No contexto das reportagens, The Economist trabalha com a hipótese de que os consumidores devam se sentir culpados pela crise e é a partir desse contexto que o discurso da redenção aparece na referida revista:

A venda de indulgências pela Igreja Católica no início do século 16, segundo a qual as pessoas poderiam, de fato, comprar o perdão dos pecados se entregassem dinheiro suficiente, foi condenado por Martinho Lutero e outros reformadores. Hoje, alguns ambientalistas estão denunciando a "compensação" de emissões de carbono em termos semelhantes ... críticos da compensação argumentam que a possibilidade de comprar o perdão dos pecados de emissão não é substituto para não pecar em primeiro lugar. Outro problema com esquemas de compensação é a falta de normas: você pode realmente confiar naqueles que prometem eliminar as emissões em seu nome? (SINS, 2006)

O fragmento de texto, acima, aponta para a ambiguidade da ação de "consumir e se redimir", ao mesmo tempo em que demonstra o quanto é importante a garantia de empresas ambientalmente responsáveis para que a redenção ocorra. Se a primeira parte da reportagem lança mão dos críticos dos créditos de carbono a fim de questionar o processo de consumir para, em seguir, se redimir; a segunda parte já se direciona para o contexto da prática em si, questionando a lisura daqueles que prometem eliminar as emissões, deixando entrever que o ponto de chegada seria, justamente, a questão de se propor empresas ambientalmente responsáveis.

Em outro fragmento de texto, abaixo, a relação entre culpa e redenção é direta, embora The Economist aponte que esteja apenas refletindo uma prática do mercado; da mesma maneira que também estaria refletindo as saídas que o mercado tem buscado para a redenção pelo consumo. No entanto, conforme a metodologia adotada neste artigo, tomamos o veículo midiático como enunciador que adota uma posição ativa em relação aos discursos que veicula.

Se você acha que pode tornar o planeta melhor parando de comprar, pense novamente. Você pode torná-lo pior. Se você está preocupado com o meio ambiente, você pode comprar alimentos orgânicos, se você quiser ajudar os agricultores pobres, você pode fazer a sua parte através da compra de produtos do Comércio Justo, ou você pode expressar sua antipatia pelas empresas multinacionais e pela globalização negativa, comprando apenas produtos locais. E o melhor de tudo é que comprar, ao contrário de votar, é divertido, assim você pode fazer o bem e se divertir ao mesmo tempo. (SINS, 2006) 


\section{Exame: um discurso ambiental que atribui responsabilidade para o consumidor através da redenção}

No caso da revista brasileira, o desdobramento da responsabilidade para culpa e redenção é ainda mais forte, embora o tom não seja de acusação ao consumidor; esse já vem construído como alguém moralmente envolvido com a causa ambiental. A culpa é apenas pressuposta, tendo em vista que é a proposta da redenção - mediante a compra de produtos de empresas ambientalmente responsáveis - que aparece como foco principal.

Sendo uma revista atrelada ao mundo dos negócios de forma mais direta, Exame evidencia o quanto essa proximidade permite que a produção discursiva seja menos ambígua e o discurso mais unívoco. O trecho de reportagem, abaixo, demonstra como tal mentalidade é absorvida pela construção discursiva da mídia de negócios a partir da lógica da redenção:

Ao usar o Cartão Ipiranga Carbono Zero para encher o tanque, o consumidor tem o compromisso da empresa de que árvores serão plantadas para neutralizar as emissões de gases de efeito estufa do veículo (HERZOG, 2007).

Ao engajar a identidade do consumidor como responsável pelos seus atos de consumo, a mídia de negócios reflete uma lógica mercadológica de produção de culpa, ao mesmo tempo em que apresenta uma maneira de negociá-la vendendo redenção, propondo uma série de produtos e medidas que "amenizem a culpa" pelo consumo em uma sociedade permeada pelo discurso do aquecimento global, como comprar produtos orgânicos ecologicamente corretos ou investir na neutralização do carbono através, por exemplo, do plantio de árvores. Assim, o consumidor não precisaria se preocupar ao consumir produtos que já trouxessem a garantia de que ele fez a escolha certa: ao consumir produtos ecologicamente corretos, ele poderia se eximir da culpa porque alguém já teria se responsabilizado por ele. Ele teria de ser responsável, apenas, na hora de tomar a decisão sobre qual produto ou marca comprar; ou, depois do consumo, sobre como neutralizar suas pegadas ecológicas.

Se, no caso de The Economist, o consumidor ambientalmente responsável parece ter tido seu suporte principal no contexto da construção do consumidor moralmente engajado da cultura empresarial, no caso de Exame o que fica mais evidenciado é a oportunidade de negócios que se abre com a existência desse tipo de consumidor que privilegia empresas ambientalmente responsáveis. O cenário da crise ambiental e o discurso da culpa que emerge nesse contexto são reconfigurados tendo como motivação principal as oportunidades de negócios.

\section{Consumo, escatologia e culpa: resignificando a crise ambiental}

Ao buscar entender a emergência da atual ideologia verde, Stravakakis (2000) pontua seu surgimento entre os anos 1960 e 1970, como produto de uma articulação entre 
uma série de elementos políticos e em torno de certa concepção da natureza. A problemática do consumo já é passível de ser localizada nessa periodização histórica, embora não apareça na perspectiva do movimento ambiental hegemônico. No relatório "Os limites do crescimento", publicado em 1972 e que é considerado um marco na história do movimento ambiental, não há nenhuma menção explícita à questão do consumo como atividade social. Para Portilho (2005), um evento que marca claramente o deslocamento discursivo da produção para o consumo foi a Eco-92, a Conferência das Nações Unidas sobre o Meio Ambiente e o Desenvolvimento (CNUMAD), realizada no Rio de Janeiro, em 1992.

Apesar da importância do consumo como fator de crise ambiental, isso não pode ser considerado suficiente para provocar a consciência ambiental no público mais amplo. Segundo Yearley (1991, p.103), “a existência de problemas sociais depende igualmente da existência contínua de grupos ou agências que definem algumas condições como um problema e objetivam fazer algo a respeito". Para o autor, os grupos ambientalistas e a mídia têm tido um papel central na promoção das questões ambientais contemporâneas junto à sociedade, a fim de gerar certa consciência ambiental.

De que maneira esses atores têm construído o discurso da crise ambiental e como o consumo aparece nesse contexto? Stravakakis argumenta que a construção dessa crise foi provocada por um deslocamento da nossa concepção imaginária e simbólica da natureza: para além da experiência de uma crise ecológica real, tem havido um deslocamento de nossa construção imaginária e simbólica a partir da irrupção do "Real" da natureza, gerando a consequente construção da crise ambiental como um sério e urgente problema social.

O autor se apoia nas análises lacanianas, em especial na leitura que Žižek (1993) faz sobre o modo pelo qual a crise ecológica tem iniciado um período de encontro com o Real, posto que a nossa representação da natureza, que sempre incorporou uma noção de severidade e imprevisibilidade das forças naturais, tem sofrido novos abalos na contemporaneidade. Žižek (2011, p.430) sugere uma nova torção ao título do estudo freudiano sobre o mal-estar na cultura já que, hoje, "o descontentamento passa da cultura para a própria natureza: ela agora surge como o mecanismo frágil que pode explodir a qualquer momento de forma catastrófica". Cada época buscou integrar uma concepção de natureza, ao mesmo tempo em que procurava dominá-la. Segundo Stravakakis (2000),

nas modernas e seculares sociedades tecno-científicas, é usualmente a ciência que providencia o aparato necessário para a simbolização da natureza. Prever o imprevisível, gerir o impossível, reduzir a expectativa através de um sistema de controle; em outras palavras, simbolizar, integrar o real da natureza, é o objetivo do discurso da ciência, em especial através de sua popularização pela mídia. (p.108)

Esse ideal está em crise. A ciência, sob a forma do desenvolvimento tecnológico, tem sido acusada de provocar a crise ambiental. O discurso midiático, reflexo dos discursos 
organizacionais em torno da sustentabilidade, procura insistir no papel da ciência como forma de lidar com a crise, mas os analistas da crise ambiental têm insistido na impossibilidade da ciência dar conta dos desafios da degradação ambiental, a não ser mediante uma mudança radical do nosso modelo de desenvolvimento. É nesse contexto, em que se apontam os limites da Natureza, que a crítica ao consumo emerge, dado que a estruturação da sociedade de consumo se dá a partir da ideia de que a natureza é um objeto de consumo sem limite.

Aqui, cabe perguntar: "qual é a relação entre as consequências de uma sociedade subjetivamente calcada no consumismo e certa representação da natureza?". Esses foram os questionamentos endereçados por Corbucci (2011) ao investigar o imaginário dominante a respeito da 'Natureza' e 'da vida futura' na construção dos discursos ambientais, a partir de uma análise de imagens veiculadas por campanhas de conscientização ambiental generalizada na mídia. Lançando mão de uma abordagem psicanalítica, a autora conclui que o que há em jogo nessas imagens é uma "estética da pulsão de morte", a partir da retratação de ambientes degradados e fenômenos apocalípticos.

Esse cenário escatológico, de destruição da espécie humana, é, de fato, recorrente nos relatórios ambientais e na mídia e tem convocado o sentimento de culpa, "algo que é próprio do impasse do homem com a cultura e a civilização, independente de em qual formação cultural ela se desenvolve" (CORBUCCI, 2011, p.163). Discursos sobre catástrofes ambientais relacionados à culpabilização de nossos atos cotidianos de consumo também têm sido recorrentes em documentários (como em "Uma Verdade Inconveniente", do ex-vice-presidente americano Al Gore), e em filmes como "O Dia depois de amanhã", para ficarmos apenas com dois exemplos evidentes.

O que os dados desta pesquisa revelam, porém, é que na mídia de negócios as referências às catástrofes ambientais, à necessidade de salvação do planeta, à exterminação de certas espécies, não dão a tônica. Tais temas se encontram dispersos em meio aos textos, sub-repticiamente, apenas para sustentar outros argumentos centrais: o poder da ciência e da tecnologia na resolução do problema, o papel pró-ativo das empresas na resposta à crise ambiental, a culpa do consumidor e a possibilidade de sua redenção pelo mercado. A produção da culpa, em especial, é aderente a esse cenário mais amplo de crise e de possibilidade de uma hecatombe ambiental que a mídia mais ampla veicula; porém, é ressaltada a possibilidade do consumidor se redimir a partir do consumo correto.

Conforme vimos, um dos pontos nodais do discurso midiático-mercadológico analisado foi "ambiente", em uma rearticulação na qual a crise ambiental não é apresentada da perspectiva da Natureza, mas a partir dos agentes centrais desse processo, que são as empresas e os consumidores responsáveis. Seguindo a teoria do discurso vimos, portanto, como a construção do consumidor responsável pela mídia de negócios pode ser entendida como a articulação de um número de elementos pré-existentes (mudanças climáticas, crise ambiental, responsabilidade, consciência ecológica) dentro de uma nova configuração que transforma esses significados, produzindo um novo conjunto discursivo que resulta 
na proposta da redenção como mercadoria. Não é preciso parar de consumir, mas consumir do jeito certo, das empresas certas. Tal perspectiva revela que há salvação do mercado e pelo mercado, assentada em uma visão de fim do mundo que tem produzido a ideia de redenção pelo consumo.

\section{Considerações Finais}

É possível afirmar que o consumidor responsável construído nas páginas da mídia de negócios apresenta-se como um ser solitário, mas bem informado, que sabe exigir e punir as empresas que não atendem aos seus ideais de sustentabilidade, que deve sentir culpa pela degradação ambiental e que pode conseguir sua redenção a partir da escolha correta das empresas ambientalmente responsáveis.

Isso ocorre porque a mídia de negócios rearticula o discurso da culpabilização do consumidor presente no discurso da crise ambiental. A rearticulação desse discurso pelo mercado resulta na proposta da redenção como mercadoria.

Em outras palavras, a culpa, que vem sendo produzida pelo novo paradigma ambiental, que tem produzido uma visão escatológica, de fim da espécie humana, por conta do hiperconsumismo das sociedades modernas, é resignificada pela mídia de negócios. No contexto midiático-mercadológico, a ideia do fim persiste, mas é recoberta pela lógica de que é possível continuar consumindo, desde que seja de empresas ambientalmente responsáveis. A escolha dessas empresas, feita de forma responsável pelos consumidores, garante que o consumo de cada um não provoque o fim de todos.

Isleide A. Fontenelle é doutora em Sociologia-USP e professora da FGV-SP

idefontenelle@uol.com.br

\section{Referências}

BEYOND waste. The Economist, London-UK, 25 jun.1998. Disponível em:<http://www.economist. com/node/372869>. Acesso em 18 nov.2012.

CAN business be cool? . The Economist, London-UK, 8 jun.2006. Disponível em:< http://www. economist.com/node/7037026>. Acesso em 18 nov.2012

CARUANA, R.; CRANE, A. 'Constructing consumer responsibility: exploring the role of corporate communications'. Organization Studies, 29(12):1495-1519, 2008.

CONNOLLY, J.; PROTHERO, A. 'Green consumption: life politics, risk and contradictions'. Journal of Consumer Culture, 8 (1):117-145, 2008.

CORBUCCI, F. A Estética da pulsão de morte na conscientização ambiental: paradoxos e sintomas do imaginário ecológico. Dissertação de Mestrado. PUC, São Paulo, 2011. 
DAVIES, A.; ELLIOTT, R. 'The evolution of the empowered consumer', European Journal of Marketing, Vol.40 (9):1.106-1.121, 2006.

GLYNOS, J.; HOWARTH, D. Logics of critical explanation in social and political theory. London: Routledge,2007.

HERZOG.,A.L. O discurso verde. Exame, São Paulo, Ed.0903, 04 out. 2007. Disponível em:< http:// exame.abril.com.br/revistaexame/edicoes/0903/noticias/-odiscurso-verde-m0139864>. Acesso em 18 nov. 2012.

HOLT, D. "Why do brands cause trouble? A dialectical theory of consumer culture and branding". Journal of Consumer Research, 29(June), pp.3-37, 2002.

HOW green is your market? The Economist, London-UK, 06 jan.2000. Disponível em: $<$ http://www. economist.com/node/271970>. Acesso em 18 nov.2012.

LACAN, J. O Seminário, livro 10: a angústia. Rio de Janeiro, Jorge Zahar Ed, 2005.

O Seminário, livro 16: de um outro ao outro. Rio de Janeiro, Jorge Zahar Ed, 2008.

LACLAU, E.; MOUFFE, C. Hegemony and socialist strategy: towards a radical democratic politics. London, Verso, 2001.

LACLAU, E. 'Foreword', in D. Howarth, A. Norval and Y. Stavrakakis(eds). Discourse theory and political analysis: Identities, hegemonies and social change. Manchester/New York: Manchester University press, 2000.

New reflections on the revolution of our time. London: Verso, 1990.

PORTILHO, F. Sustentabilidade ambiental, consumo e cidadania. São Paulo: Cortez, 2005.

RICHERS, R. Os surfistas é que estão certos. Exame, São Paulo, Ed.0601, 17 jan.1996. Disponível em:< http://exame.abril.com.br/revista-exame/edicoes/0601/noticias/os-surfistas-e-que-estaocertos-m0053169>. Acesso em 18 nov. 2012.

SINS of emission. The Economist, London-UK, 03 ago.2006. Disponível em: $<$ http://www.economist. com/node/7252897>. Acesso em 18 nov.2012.

STAVRAKAKIS, Y. 'Ambiguous ideology and the Lacanian twist', Journal of the Centre for Freudian Analysis and Research, 8 \& 9: 117-130, 1997.

' 'On the emergence of green ideology: the dislocation factor in green politics', in D. Howarth, A. Norval and Y. Stavrakakis(eds). Discourse theory and political analysis: Identities, hegemonies and social change. Manchester/New York: Manchester University press, 2000.

TEIXEIRA JR., S. Novo Clima para os negócios. Exame, São Paulo, Ed.0883, 14 dez. 2006. Disponível em:< http://exame.abril.com.br/revista-exame/edicoes/0883/noticias/novo-clima-paraos-negocios-m0118941>. Acesso em 18 nov.2012.

YEARLEY, S. The Green Case. London: Harper Collins, 1991.

ŽIŽEK, S. Como ler Lacan. Rio de Janeiro: Zahar, 2010.

. Em defesa das causas perdidas. São Paulo: Boitempo, 2011.

Tarrying with the Negative. Durham: Duke University Press, 1993.

Artigo recebido em setembro e aprovado em outubro de 2013. 